\title{
Optimization through the Levenberg-Marquardt Backpropagation Method for a Magnetohydrodynamic Squeezing Flow System
}

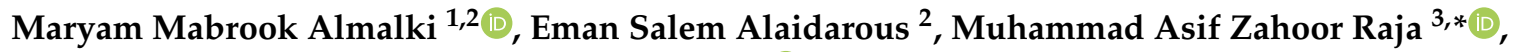 \\ Dalal Adnan Maturi ${ }^{2}$ and Muhammad Shoaib ${ }^{4}$ (D) \\ 1 Department of Mathematics, Faculty of Science, Umm Al-Qura University, Makkah 24211, Saudi Arabia; \\ mmmalki@uqu.edu.sa \\ 2 Department of Mathematics, Faculty of Science, King Abdulaziz University, Jeddah 21589, Saudi Arabia; \\ ealaidarous@kau.edu.sa (E.S.A.); dmaturi@kau.edu.sa (D.A.M.) \\ 3 Future Technology Research Center, National Yunlin University of Science and Technology, \\ 123 University Road, Section 3, Douliou, Yunlin 64002, Taiwan \\ 4 Department of Mathematics, COMSATS University Islamabad, Attock Campus, Attock 43600, Pakistan; \\ dr.shoaib@cuiatk.edu.pk \\ * Correspondence: rajamaz@yuntech.edu.tw
}

check for updates

Citation: Almalki, M.M.; Alaidarous, E.S.; Raja, M.A.Z.; Maturi, D.A.; Shoaib, M. Optimization through the Levenberg-Marquardt

Backpropagation Method for a Magnetohydrodynamic Squeezing Flow System. Coatings 2021, 11, 779 https://doi.org/10.3390/ coatings11070779

Academic Editor: Rahmat Ellahi

Received: 16 May 2021

Accepted: 12 June 2021

Published: 29 June 2021

Publisher's Note: MDPI stays neutral with regard to jurisdictional claims in published maps and institutional affiliations.

Copyright: (c) 2021 by the authors. Licensee MDPI, Basel, Switzerland. This article is an open access article distributed under the terms and conditions of the Creative Commons Attribution (CC BY) license (https:/ / creativecommons.org/licenses/by/ $4.0 /)$.

\begin{abstract}
The present study introduced the unsteady squeezing flow of two-dimensional viscous fluid with nanoparticles between two disks by using the Levenberg-Marquardt backpropagated neural network (LMB-NN). Conversion of the partial differential equations (PDEs) into equivalent ordinary differential equations (ODEs) is performed by suitable similarity transformation. The data collection for suggested (LMB-NN) is made for various magnetohydrodynamic squeezing flow (MHDSF) scenarios in terms of the squeezing parameter, Prandtl number, Brownian motion parameter, and the thermophoresis parameter by employing the Runge-Kutta technique with the help of Mathematica software. The worth of the proposed methodology has been established for the proposed solver (LMB-NN) with different scenarios and cases, and the outcomes are compared through the effectiveness and reliability of mean square error (MSE) for the squeezing flow problem MHDSF. Moreover, the state transition, Fitness outline, histogram error, and regression presentation also endorse the strength and reliability of the solver LMB-NN. The high convergence between the reference solutions and the solutions obtained by incorporating the efficacy of a designed solver LMB-NN indicates the strength of the proposed methodology, where the accuracy level is achieved in the ranges from $10^{-6}$ to $10^{-12}$.
\end{abstract}

Keywords: squeezing flow; magnetohydrodynamic; nanoparticles; brownian motion; thermophoresis; Levenberg-Marquardt backpropagated; neural network; similarity transformation

\section{Introduction}

The flow between two moving parallel plates toward each other is called squeezing flow. Recently, scientists and engineers have been interested in related research with squeezing flow due to its valuable use in industries like liquid metals, injection shaping, lubrication, food, and polymer processing. Stefan [1] reported the first paper authored on the squeezing flow under lubrication approximation. Studies continued on the same problem, and, in 1886, Rooynolds [2] presented a solution for elliptic plates, in particular. Atlas et al. [3] developed a numerical solution for unsteady nanofluid flows between two parallel plates using the finite difference method. Domairry and Hatami [4] investigated squeezing Cu-Water nanofluid flow using a differential transformation method (DTM). Domairry and Aziz [5] studied magneto-hydrodynamic (MHDSF) between two parallel disks with effects such as suction or injection of the fluid by implementing the homotopy perturbation method (HPM). 
To improve energy transfer fluids' thermal conductivity, scientists immersed nanoparticles in the basic fluids, creating a new type of fluid known as nanofluid. This fluid type is considered important as it enters into many modern applications due to these fluids' new properties. Magnetic nanofluids will likely have a significant role in the future in cancer treatment and directing particles in the bloodstream. Buongiorno [6] studied the thermal properties of base fluids by improving the mathematical model containing the effects of Brownian motion and thermophoresis. Khan and Pop [7] used the Keller-box method to analyze nanofluid's two-dimensional flow over a linearly stretching surface. Turkyilmazoglu [8] investigated the transfer effect of heat and mass on MHD flow based on slip conditions and different kinds of nanoparticles. More studies for nanofluids in various dimensions are cited [9-14].

The aforementioned numerical methods that are used to solve various problems have merits and demerits. Therefore, a stochastic computing system is discovered to find answers to complicated nonlinear problems, and, despite this, it was only entered quickly to solve the squeezing flow model's governing system. The stochastic computing solvers benefit from computing through artificial neural networks (ANN) systems and its improvement in answering complicated problems in terms of the system of ordinary or partial equations.

Stochastic numerical computing solvers have many different applications in numerous domains and areas, for example, plasma physics [15], finance models [16,17], the mechanics of fluid [18-21], the different system of pantograph and Emden-Fowler equations [22-25], biological studies [26-28], mosquito dispersal model [29], and studies of atomic physics [30]. Some more recent research work related to the soft computing paradigms for the different fluid flow systems under the impacts of heat transfer and magnetohydrodynamics is also provided in the references [31-33]. The structure of our treatment is illustrated as follows:

- A soft computing technique-based Levenberg-Marquardt algorithm is used to solve the fluid flow problem MHDSF.

- Mathematical simplification is presented for MHDSF in terms of partial differential equations to be easier in dealing with the proposed model (LMB-NN).

- Creation of the data set for a suggested (LMB-NN) based on squeezing parameter, Prandtl number, Brownian motion parameter, and thermophoresis parameter is used in solution (MHDSF) by employing the Runge-Kutta technique for various scenarios and cases.

- The processes of training, testing, and validation that are created with (LMB-NN) is implemented for every scenario and case of (MHDSF) to find the approximate solution and comparison with standard results.

- The performance of NN-BLMS is established through convergence plots of mean squared error-based fitness/merit function, state transition, regression metrics, and histogram error.

The plan for the rest of the paper is as follows: The problem formulation of (MHDSF) is explored in Section 2. The Levenberg-Marquardt algorithm to obtain the solution to the problem is discussed in Section 3. The numerical and graphical results are provided in Section 4. Conclusions are provided in the last section.

\section{Mathematical Formulation}

We consider the unsteady squeezing flow of an incompressible two-dimensional viscous nanofluid between two infinite parallel disks Figure 1. The upper disk at $y=h(t)=\left(\frac{v(1-\gamma t)}{a}\right)^{\frac{1}{2}}$ moves toward the lower stationary disk at $y=0$ with velocity $v_{h}=\frac{d h}{d t}$. Stretching velocity to the lower disk is $\frac{a x}{(1-\gamma t)}$ and, for $\gamma=0$, the linearly stretching procedure approaches stability in the presence of a magnetic field. Moreover, the effects of thermophoresis and Brownian motion are preserved while neglecting the electric field and Hall effects. 


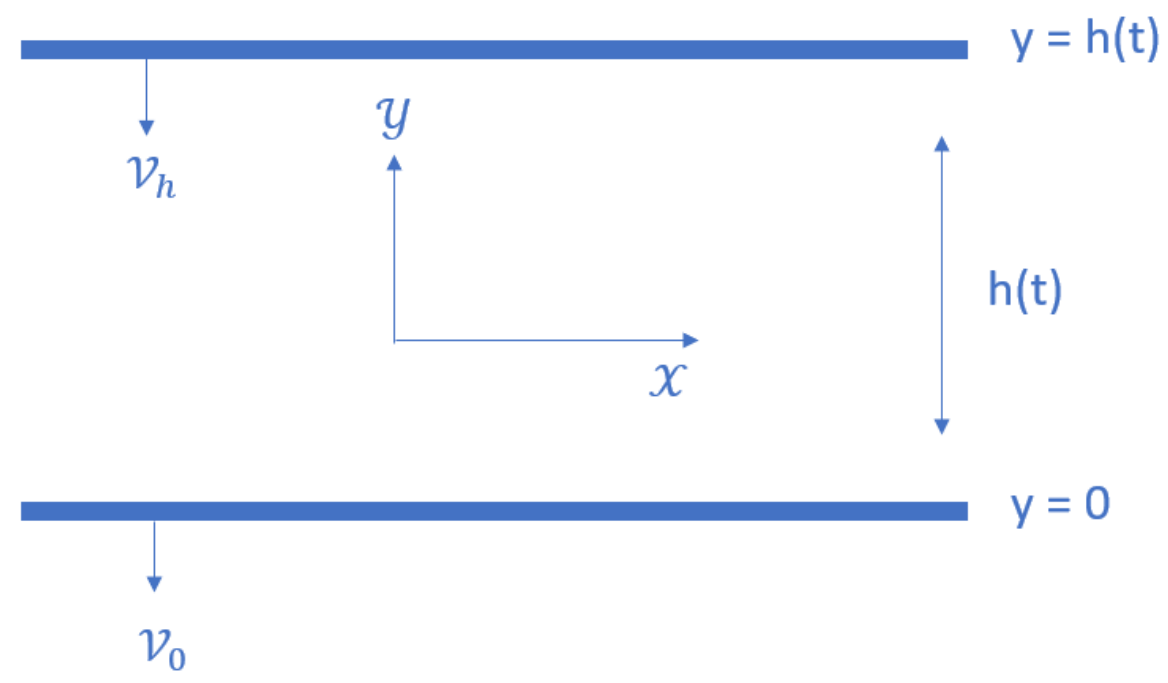

Figure 1. Configuration of the system.

The governing of mass, momentum, energy, and nanoparticle concentration partial differential equations are given as follows [34]:

$$
\begin{gathered}
\frac{\partial u}{\partial x}+\frac{\partial v}{\partial y}=0 \\
\frac{\partial u}{\partial t}+u \frac{\partial u}{\partial x}+v \frac{\partial u}{\partial y}=-\frac{1}{\rho_{f}} \frac{\partial p^{*}}{\partial x}+v\left(\frac{\partial^{2} u}{\partial x^{2}}+\frac{\partial^{2} u}{\partial y^{2}}\right)-\frac{\sigma B_{0}^{2}}{\rho_{f}(1-\gamma t)} u \\
\frac{\partial v}{\partial t}+u \frac{\partial v}{\partial x}+v \frac{\partial v}{\partial y}=-\frac{1}{\rho_{f}} \frac{\partial p^{*}}{\partial x}+v\left(\frac{\partial^{2} v}{\partial x^{2}}+\frac{\partial^{2} v}{\partial y^{2}}\right) \\
\frac{\partial T}{\partial t}+u \frac{\partial T}{\partial x}+v \frac{\partial T}{\partial y}=\alpha\left(\frac{\partial^{2} T}{\partial x^{2}}+\frac{\partial^{2} T}{\partial y^{2}}\right)+\frac{(\rho c)_{p}}{(\rho c)_{f}} D_{b}\left(\frac{\partial T}{\partial x} \frac{\partial C}{\partial x}+\frac{\partial T}{\partial y} \frac{\partial C}{\partial y}\right) \\
+\frac{(\rho c)_{p}}{(\rho c)_{f}} \frac{D_{t}}{T_{M}}\left(\left(\frac{\partial T}{\partial x}\right)^{2}+\left(\frac{\partial T}{\partial y}\right)^{2}\right) \\
\frac{\partial C}{\partial t}+u \frac{\partial C}{\partial x}+v \frac{\partial C}{\partial y}=D_{b}\left(\frac{\partial^{2} C}{\partial x^{2}}+\frac{\partial^{2} C}{\partial y^{2}}\right)+\frac{D_{t}}{T_{M}}\left(\frac{\partial^{2} T}{\partial x^{2}}+\frac{\partial^{2} T}{\partial y^{2}}\right)
\end{gathered}
$$

subject to the boundary conditions

$$
\begin{aligned}
& u=U_{0}=\frac{a x}{1-\gamma t}, v=\frac{V_{0}}{1-\gamma t}, T=T_{0}, C=C_{0} \text { at } y=0, \\
& u=0, v=v_{h}=\frac{d h}{d t}=-\frac{\gamma}{2}\left(\frac{v}{a(1-\gamma t)}\right)^{\frac{1}{2}}, T=T_{0}+\left(\frac{T_{0}}{(1-\gamma t)}\right), \\
& C=C_{0}+\left(\frac{C_{0}}{(1-\gamma t)}\right), \text { at } y=h(t) .
\end{aligned}
$$

where $V_{0}>0$ represents the suction, and $V_{0}<0$ is the injection/blowing velocity. By using the similarity transformation, the above system yields

$$
\begin{gathered}
f^{\prime \prime \prime \prime}+f f^{\prime \prime \prime}-f^{\prime} f^{\prime \prime}-\frac{\mathrm{Sq}}{2}\left(3 f^{\prime \prime}+\eta f^{\prime \prime \prime}\right)-M^{2} f^{\prime \prime}=0, \\
\theta^{\prime \prime}+\operatorname{PR}\left(f \theta^{\prime}-\frac{\mathrm{Sq}}{2}\left(2 \theta+\eta \theta^{\prime}\right)+\mathrm{Nb} \theta^{\prime} \phi^{\prime}+\mathrm{N} t \theta^{\prime 2}\right)=0,
\end{gathered}
$$




$$
\phi^{\prime \prime}+\text { Le PR }\left(f \phi^{\prime}-\frac{\mathrm{Sq}}{2}\left(2 \phi+\eta \phi^{\prime}\right)\right)+\frac{\mathrm{Nt}}{\mathrm{Nb}} \theta^{\prime \prime}=0,
$$

with the following boundary conditions:

$$
\begin{aligned}
& f(0)=\mathrm{S}, f^{\prime}(0)=1, \theta(0)=0, \phi(0)=0, \\
& f(1)=\frac{\mathrm{Sq}}{2}, f^{\prime}(1)=0, \theta(1)=1, \phi(1)=1 .
\end{aligned}
$$

These parameters are defined by

$$
\begin{gathered}
\mathrm{Sq}=\frac{\gamma}{a}, M^{2}=\frac{\sigma B_{0}^{2}}{\rho_{f} a}, \mathrm{~S}=\frac{v_{0}}{a h(t)}, \mathrm{PR}=\frac{v}{\alpha}, \mathrm{Le}=\frac{\alpha}{D_{b}}, \\
\mathrm{Nb}=\frac{(\rho c)_{p} D_{b} C_{0}}{(\rho C)_{f} v(1-\gamma t)}, \mathrm{Nt}=\frac{(\rho c)_{p} D_{t} T_{0}}{(\rho C)_{f} v T_{M}(1-\gamma t)}
\end{gathered}
$$

\section{Solution Methodology}

The Levenberg-Marquardt neural network is an algorithm used in nonlinear training. It is proposed for improving the learning algorithm in each of the conjugate gradient and Quasi-Newton methods, where it designs to verify the locally fast convergence speed and achieve better performance in general. The architecture of LMB-NN is shown in Figure 2.

The necessary description of methodology based on neural networks, including the layer structure, hidden neurons, topology of the networks, and arbitrary selection of an input and target data set for training, testing, and validation samples, is determined to solve the problem. With the help of using the "nftoo" command in the neural network toolbox, the suggested LMB-NN is implemented in the MATLAB environment. The total amount of data for LMB-NN is 1001 found between 0 and 1 by setting 0.001 as the stepsize and using the Runge-Kutta technique through "NDSolve" in Mathematica.

These data are distributed randomly for $f, f^{\prime}, \theta$, and $\phi$ into sets: training, testing, and validation to achieve the best convergence. In this problem, we chose the sets as follows:

- $90 \%$ of the data for the training.

- $5 \%$ of the data for the testing.

- $5 \%$ of the data for the validation.

The number of neurons is also arbitrary; selecting 40 gives a good accuracy of the computational results as shown in Figure 3.

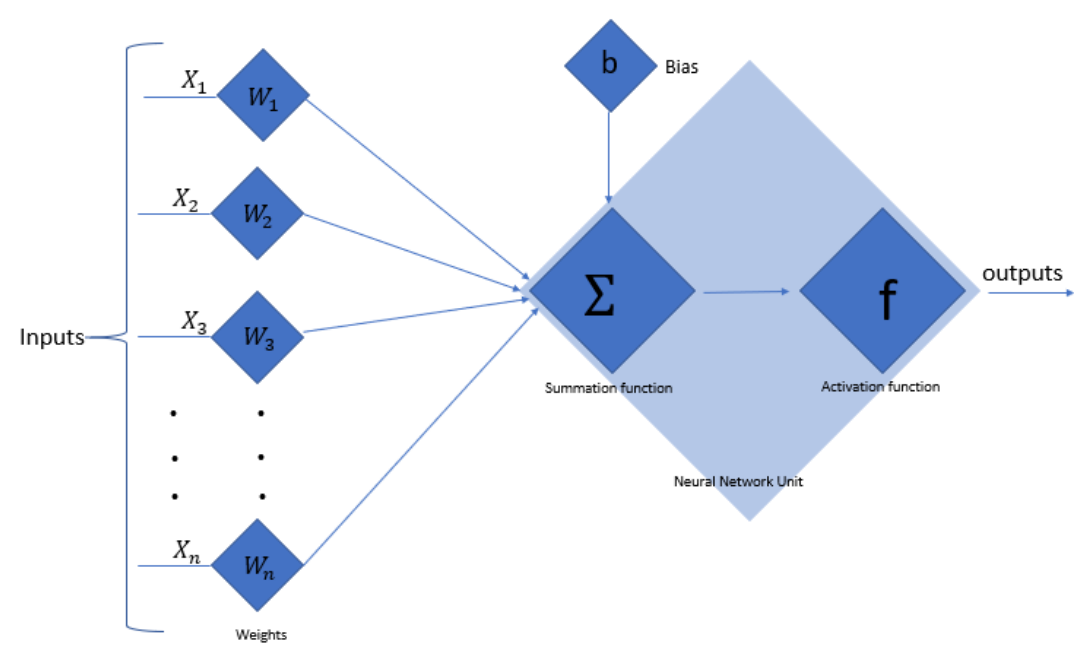

Figure 2. Design of a single neural network. 


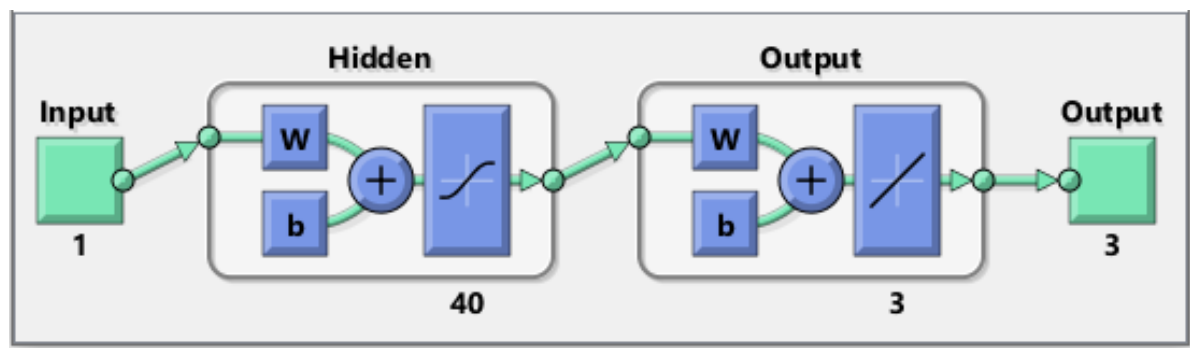

Figure 3. Model generated using the NN toolbox.

\section{Results and Discussion}

The system of ordinary differential equations of magnetohydrodynamic nanofluid between two parallel plates Equations (7)-(10) is offered here for numerical experimentation of LMB-NN for each case of all scenarios. The scheme of working the LMB-NN is offered in Figure 4. The impact of the variation of different scenarios and cases is listed in Table 1. The graphs and tables below present the numerical results of some exciting parameters on interest profiles.

Table 1. Variation of different scenarios and cases involved.

\begin{tabular}{|c|c|c|c|c|c|c|c|c|}
\hline \multirow{2}{*}{ Scenario } & \multirow{2}{*}{ Case } & \multicolumn{7}{|c|}{ Physical Quantities of Interest } \\
\hline & & $S$ & $M$ & $\mathrm{Nb}$ & $N t$ & $S q$ & Le & $P R$ \\
\hline \multirow{4}{*}{$\begin{array}{c}(1) \\
\text { Variation in } \\
\quad S q\end{array}$} & 1 & 0.5 & 0.5 & 0.5 & 0.2 & 0.0 & 1.0 & 1.0 \\
\hline & 2 & 0.5 & 0.5 & 0.5 & 0.2 & 0.5 & 1.0 & 1.0 \\
\hline & 3 & 0.5 & 0.5 & 0.5 & 0.2 & 1.0 & 1.0 & 1.0 \\
\hline & 4 & 0.5 & 0.5 & 0.5 & 0.2 & 1.5 & 1.0 & 1.0 \\
\hline \multirow{4}{*}{$\begin{array}{c}(2) \\
\text { Variation in } \\
P R\end{array}$} & 1 & 0.5 & 0.5 & 0.5 & 0.2 & 1.0 & 1.0 & 0.5 \\
\hline & 2 & 0.5 & 0.5 & 0.5 & 0.2 & 1.0 & 1.0 & 1.0 \\
\hline & 3 & 0.5 & 0.5 & 0.5 & 0.2 & 1.0 & 1.0 & 1.5 \\
\hline & 4 & 0.5 & 0.5 & 0.5 & 0.2 & 1.0 & 1.0 & 2.0 \\
\hline \multirow{4}{*}{$\begin{array}{c}(3) \\
\text { Variation in } \\
\mathrm{Nb}\end{array}$} & 1 & 0.5 & 0.5 & 0.5 & 0.2 & 1.0 & 1.0 & 1.0 \\
\hline & 2 & 0.5 & 0.5 & 1.0 & 0.2 & 1.0 & 1.0 & 1.0 \\
\hline & 3 & 0.5 & 0.5 & 1.5 & 0.2 & 1.0 & 1.0 & 1.0 \\
\hline & 4 & 0.5 & 0.5 & 2.0 & 0.2 & 1.0 & 1.0 & 1.0 \\
\hline \multirow{4}{*}{$\begin{array}{c}(4) \\
\text { Variation in } \\
N t\end{array}$} & 1 & 0.5 & 0.5 & 0.5 & 0.0 & 1.0 & 1.0 & 1.0 \\
\hline & 2 & 0.5 & 0.5 & 0.5 & 0.3 & 1.0 & 1.0 & 1.0 \\
\hline & 3 & 0.5 & 0.5 & 0.5 & 0.6 & 1.0 & 1.0 & 1.0 \\
\hline & 4 & 0.5 & 0.5 & 0.5 & 1.0 & 1.0 & 1.0 & 1.0 \\
\hline
\end{tabular}

Figure 5 explains the performance interpretation of AI computing concerning main square error (MSE) for case 2 of scenarios 1, 2, 3, and 4, respectively. The minimum value of (MSE) reached in scenario 2 is estimated by $\left(1.2204 \times 10^{-12}\right)$ at $(101)$ epochs. This means that it obtained the best accuracy of the (LMB-NN) compared to the other scenarios. The fitness plots along with error dynamics for input between 0 to 1 and step size 0.001 are shown in Figure 6 for case 2 of all scenarios performed to solve (MHDSF) with LMB-NN. 


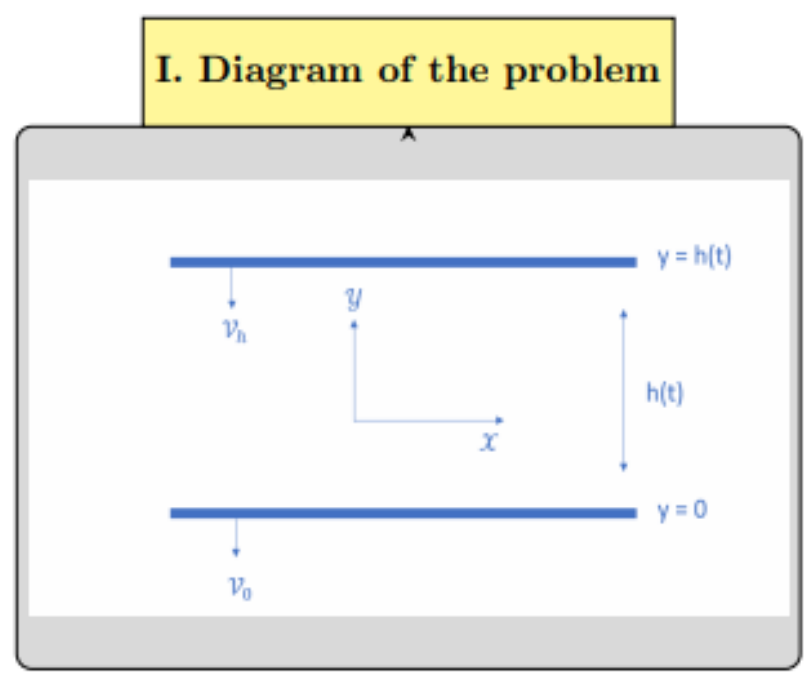

II. Mathematical Model
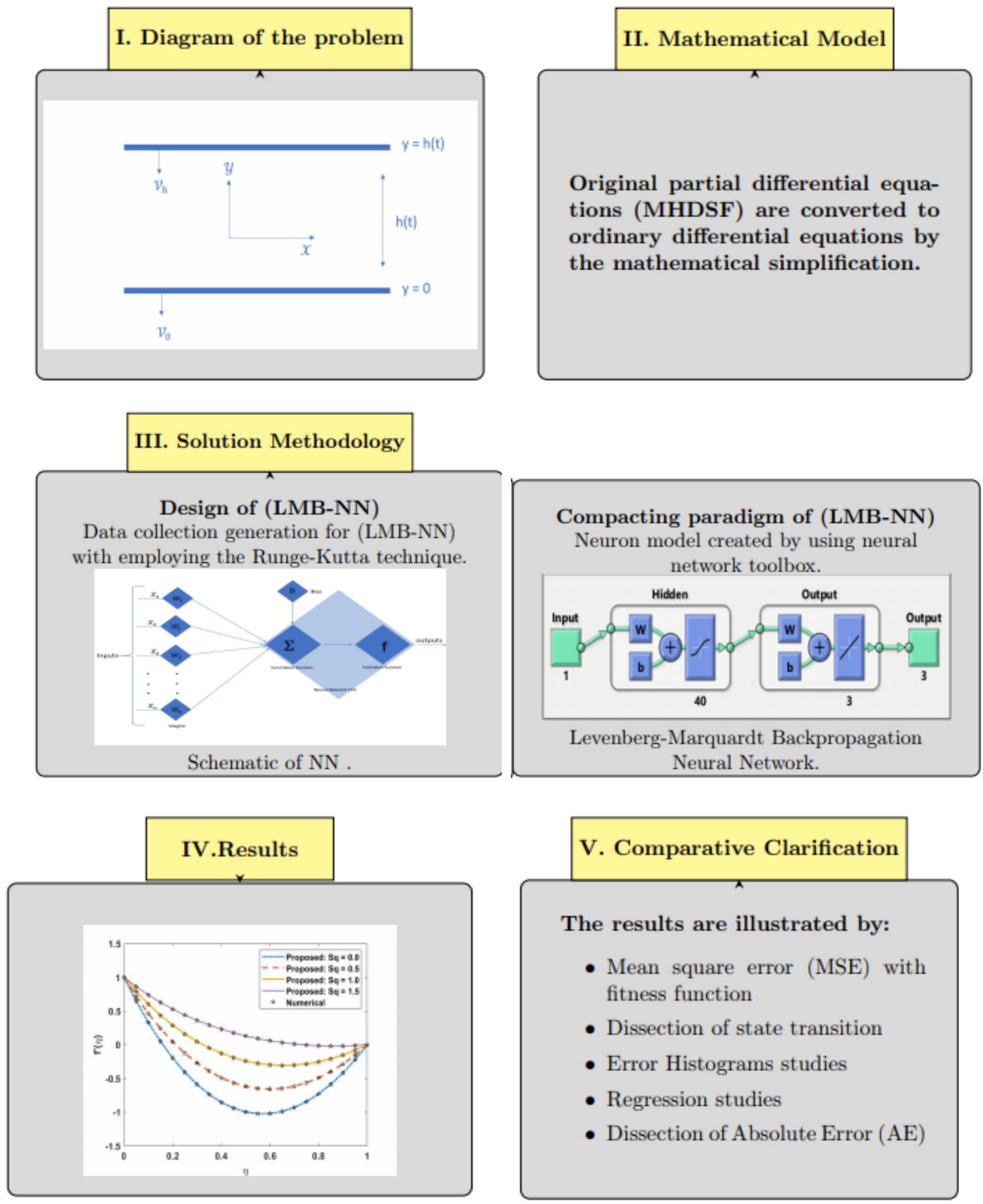

Figure 4. Work flow diagram of proposed LMB-NN for the (MHDSF) model. 


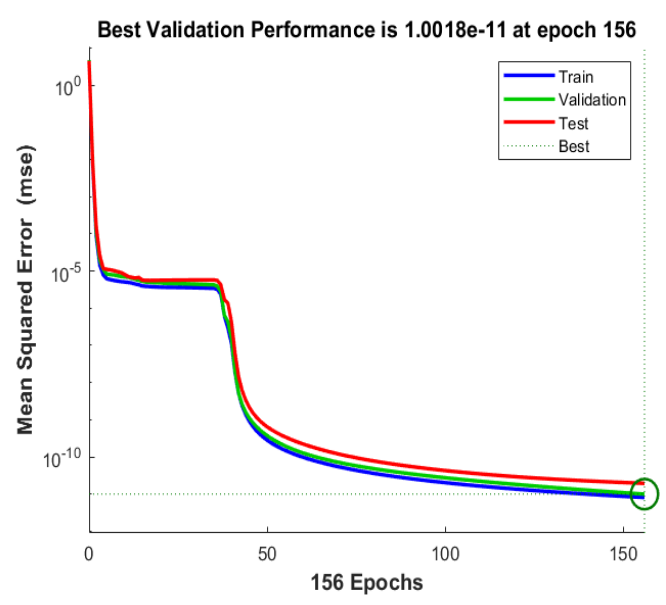

(a)

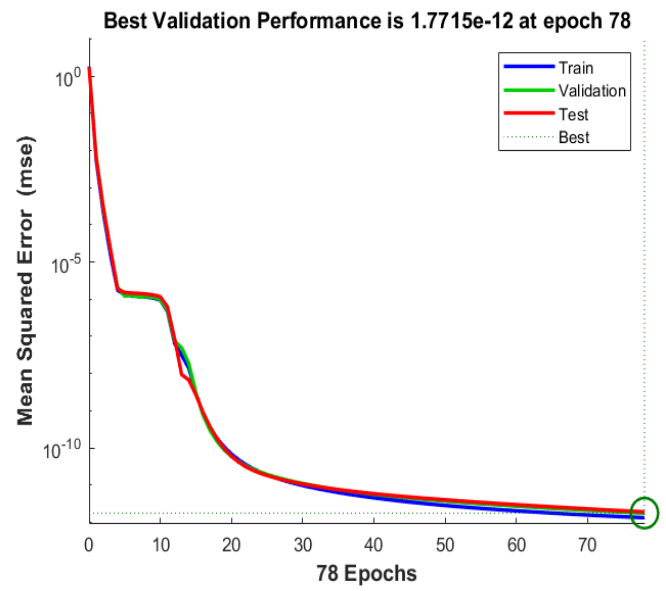

(c)

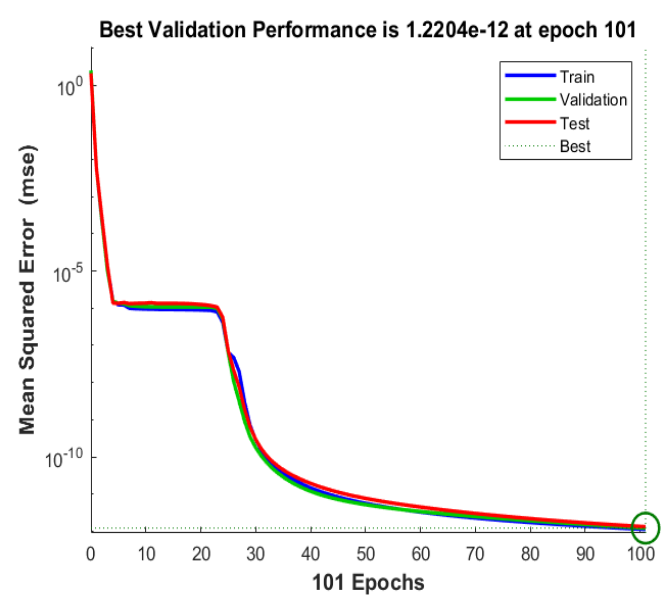

(b)

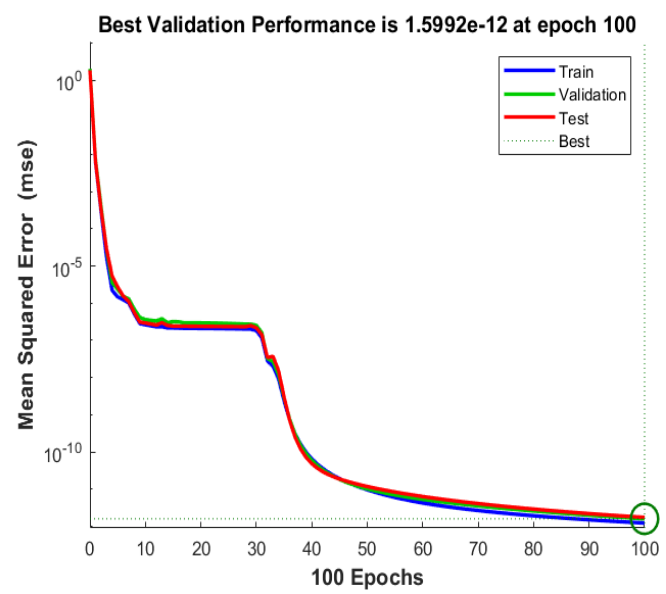

(d)

Figure 5. MSE performance of the LMB-NN paradigm for (MHDSF). (a) MSE curve for (case 2-S1); (b) MSE curve for (case 2-S2); (c) MSE curve for (case 2-S3); (d) MSE curve for (case 2-S4).

The training states of the gradient, $\mathrm{Mu}$, and validation checks are shown in Figure 7 for case 2 of scenarios 1, 2, 3, and 4, respectively. The gradient updates the weights of the neural network in the correct direction and amount, while $\mathrm{Mu}$ is the value used to control the training algorithm, and the validation check is expressed as the generalization standard of the system. The difference between targets and output values appears in Figure 8, where the zero error line indicates the smallest distance present in the error histogram. Comparing all the values referred to in Case 2 from all four scenarios shows that the smallest value was executed at $-2.2 \times 10^{-8}$, therefore achieving the proposed model's best accuracy. The regression studies are presented in Figures 9 and 10 for all training, testing, and validation that is used to solve (MHDSF), and the value of $\mathrm{R}$ is equal to one for different scenarios. Thus, the target accuracy of the proposed model has been accomplished. Therefore, the results obtained from running in LMB-NN are displayed for velocity, temperature, and concentration profiles, respectively, for different scenarios (MHDSF) close to the results we found from the Runge-Kutta method, as seen in Figure 11. The absolute error (AE) is computing to establish an accurate benchmark for comparison; Figure 12 offered the (AE) from the reference solution for all scenarios, and the smallest (AE) is shown in scenario 4. Organize the computational operations include MSE processes, performance, gradient, $\mathrm{Mu}$, epoch, and time in Table 2. 
Table 2. NN-BLMS numerical outcomes for the MHDSF system.

\begin{tabular}{|c|c|c|c|c|c|c|c|c|c|}
\hline \multirow{2}{*}{ Scenarios (S) } & \multirow{2}{*}{ Case } & \multicolumn{3}{|c|}{ Main Square Error } & \multirow{2}{*}{ Performance } & \multirow{2}{*}{ Gradient } & \multirow{2}{*}{ Mu Value } & \multirow{2}{*}{ Epochs } & \multirow{2}{*}{ Time } \\
\hline & & Training & Validation & Testing & & & & & \\
\hline \multirow{4}{*}{ (1) } & 1 & $4.76585 \times 10^{-12}$ & $6.30371 \times 10^{-12}$ & $6.3129 \times 10^{-12}$ & $4.77 \times 10^{-12}$ & $9.94 \times 10^{-8}$ & $1.00 \times 10^{-12}$ & 256 & $\leq 0.5$ \\
\hline & 2 & $8.13009 \times 10^{-12}$ & $1.00178 \times 10^{-11}$ & $1.95386 \times 10^{-11}$ & $8.13 \times 10^{-12}$ & $9.87 \times 10^{-8}$ & $1.00 \times 10^{-12}$ & 156 & $\leq 0.5$ \\
\hline & 3 & $4.31321 \times 10^{-6}$ & $3.26626 \times 10^{-6}$ & $5.19729 \times 10^{-6}$ & $3.24 \times 10^{-6}$ & $3.14 \times 10^{-5}$ & $1.00 \times 10^{-7}$ & 135 & $\leq 0.5$ \\
\hline & 4 & $1.21850 \times 10^{-11}$ & $1.54756 \times 10^{-11}$ & $1.42292 \times 10^{-11}$ & $1.22 \times 10^{-11}$ & $9.80 \times 10^{-8}$ & $1.00 \times 10^{-12}$ & 123 & $\leq 0.5$ \\
\hline \multirow{4}{*}{ (2) } & 1 & $7.63307 \times 10^{-7}$ & $1.09583 \times 10^{-6}$ & $1.02174 \times 10^{-6}$ & $7.33 \times 10^{-7}$ & $1.16 \times 10^{-6}$ & $1.00 \times 10^{-8}$ & 17 & $\leq 0.5$ \\
\hline & 2 & $1.12830 \times 10^{-12}$ & $1.22042 \times 10^{-12}$ & $1.32671 \times 10^{-12}$ & $1.13 \times 10^{-12}$ & $9.87 \times 10^{-8}$ & $1.00 \times 10^{-13}$ & 101 & $\leq 0.5$ \\
\hline & 3 & $1.26984 \times 10^{-12}$ & $1.82527 \times 10^{-12}$ & $1.74307 \times 10^{-12}$ & $1.27 \times 10^{-12}$ & $9.74 \times 10^{-8}$ & $1.00 \times 10^{-13}$ & 94 & $\leq 0.5$ \\
\hline & 4 & $1.29840 \times 10^{-12}$ & $1.77428 \times 10^{-12}$ & $1.72913 \times 10^{-12}$ & $1.30 \times 10^{-12}$ & $9.97 \times 10^{-8}$ & $1.00 \times 10^{-13}$ & 80 & $\leq 0.5$ \\
\hline \multirow{4}{*}{ (3) } & 1 & $1.25823 \times 10^{-12}$ & $1.94858 \times 10^{-12}$ & $1.80848 \times 10^{-12}$ & $1.26 \times 10^{-12}$ & $9.79 \times 10^{-8}$ & $1.00 \times 10^{-13}$ & 86 & $\leq 0.5$ \\
\hline & 2 & $1.33239 \times 10^{-12}$ & $1.77148 \times 10^{-12}$ & $1.91072 \times 10^{-12}$ & $1.33 \times 10^{-12}$ & $9.95 \times 10^{-8}$ & $1.00 \times 10^{-13}$ & 78 & $\leq 0.5$ \\
\hline & 3 & $1.20463 \times 10^{-12}$ & $1.54025 \times 10^{-12}$ & $1.25176 \times 10^{-12}$ & $1.20 \times 10^{-12}$ & $9.99 \times 10^{-8}$ & $1.00 \times 10^{-13}$ & 98 & $\leq 0.5$ \\
\hline & 4 & $1.18896 \times 10^{-6}$ & $1.60196 \times 10^{-6}$ & $1.70214 \times 10^{-6}$ & $1.11 \times 10^{-6}$ & $2.43 \times 10^{-6}$ & $1.00 \times 10^{-8}$ & 16 & $\leq 0.5$ \\
\hline \multirow{4}{*}{ (4) } & 1 & $9.73136 \times 10^{-7}$ & $1.02015 \times 10^{-6}$ & $1.16425 \times 10^{-6}$ & $9.28 \times 10^{-7}$ & $1.72 \times 10^{-6}$ & $1.00 \times 10^{-8}$ & 24 & $\leq 0.5$ \\
\hline & 2 & $1.22586 \times 10^{-12}$ & $1.59916 \times 10^{-12}$ & $1.73599 \times 10^{-12}$ & $1.23 \times 10^{-12}$ & $9.80 \times 10^{-8}$ & $1.00 \times 10^{-13}$ & 100 & $\leq 0.5$ \\
\hline & 3 & $1.11988 \times 10^{-12}$ & $1.47276 \times 10^{-12}$ & $1.21307 \times 10^{-12}$ & $1.12 \times 10^{-12}$ & $9.96 \times 10^{-8}$ & $1.00 \times 10^{-13}$ & 113 & $\leq 0.5$ \\
\hline & 4 & $1.45146 \times 10^{-6}$ & $1.64029 \times 10^{-6}$ & $1.58078 \times 10^{-6}$ & $1.41 \times 10^{-6}$ & $6.48 \times 10^{-6}$ & $1.00 \times 10^{-8}$ & 16 & $\leq 0.5$ \\
\hline
\end{tabular}

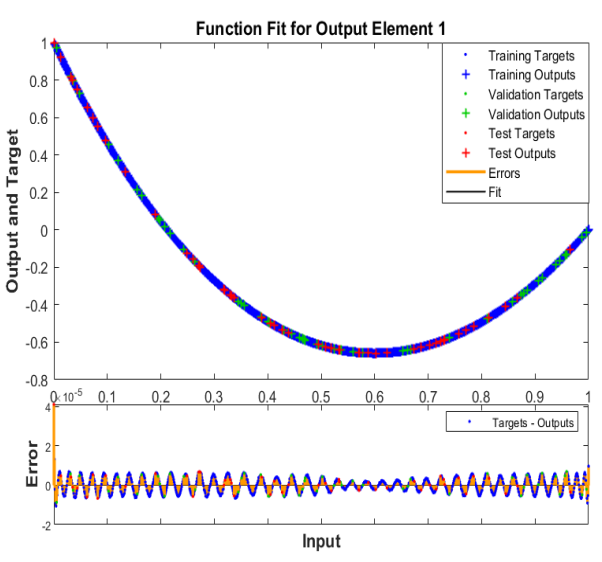

(a)

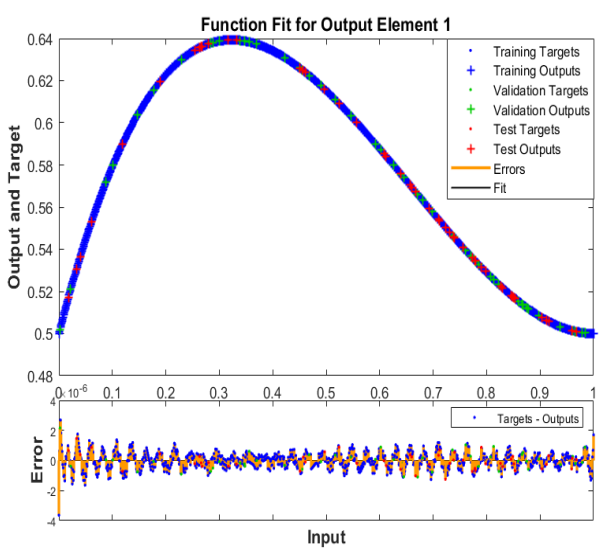

(c)

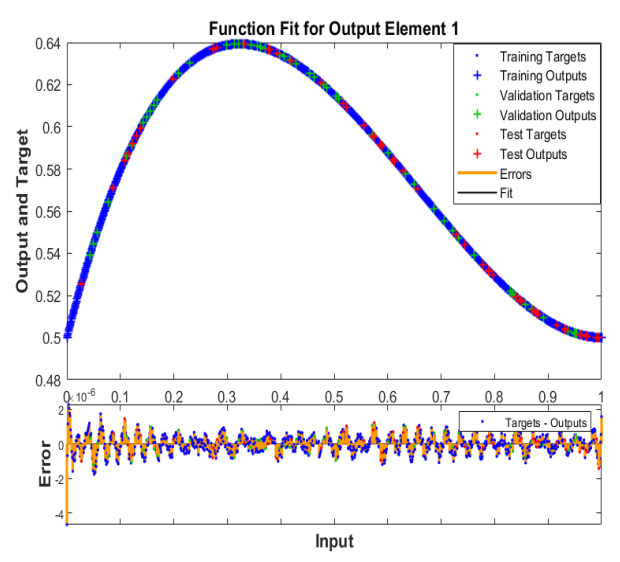

(b)

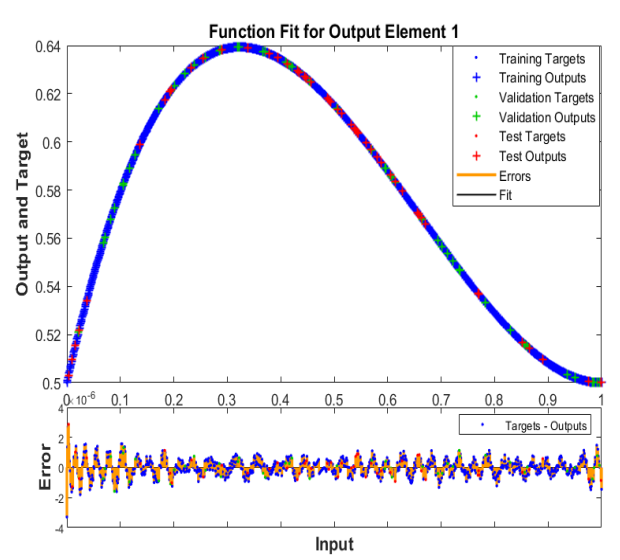

(d)

Figure 6. Assessment of the LMB-NN paradigm for (MHDSF). (a) Fitness outline for (case 2-S1); (b) Fitness outline for (case 2-S2); (c) Fitness outline for (case 2-S3); (d) Fitness outline for (case 2-S4). 


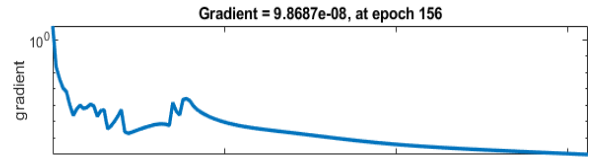

$M u=1 \mathrm{e}-12$, at epoch 156

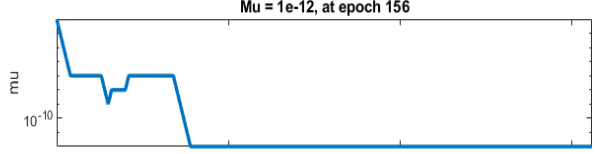

Validation Checks $=0$, at epoch 156

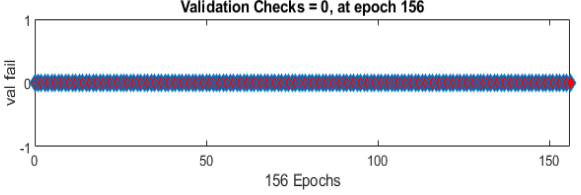

(a)
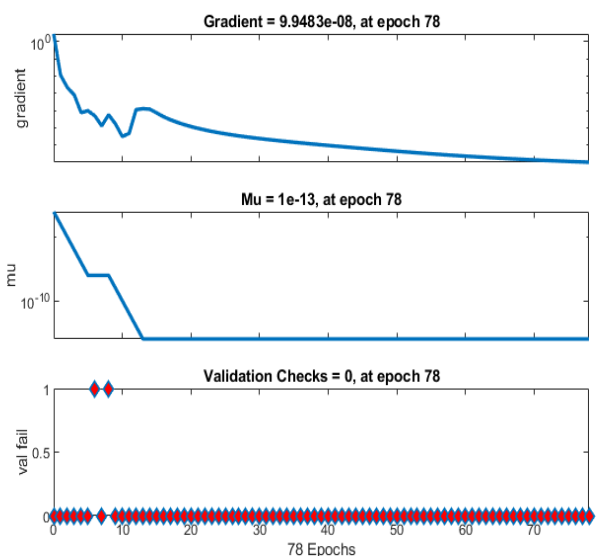

(c)

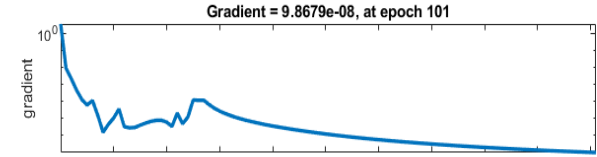

$\mathrm{Mu}=1 \mathrm{e}-13$, at epoch 101

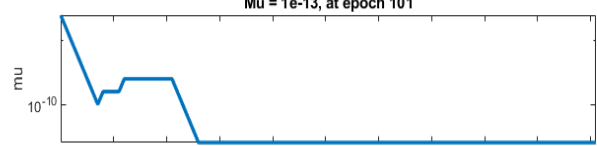

Validation Checks $=0$, at epoch 101

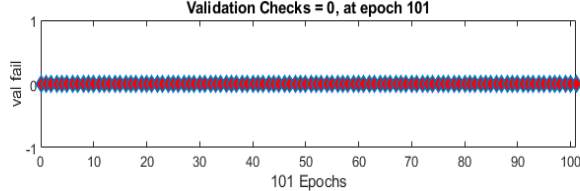

(b)

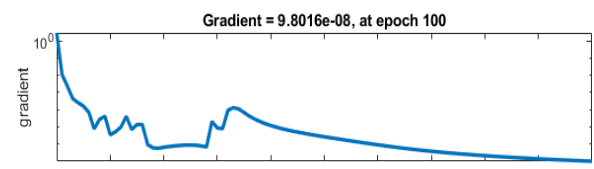

$\mathrm{Mu}=1 \mathrm{e}-13$, at epoch 100
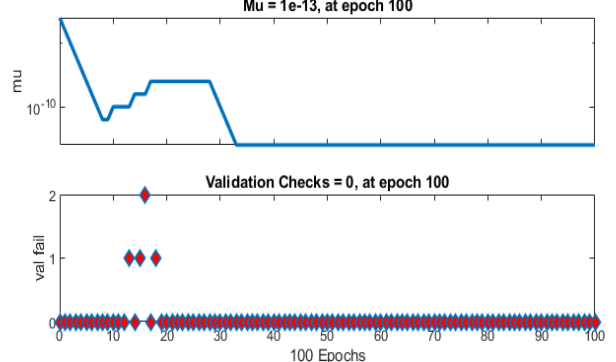

(d)

Figure 7. State transition of the LMB-NN paradigm for (MHDSF). (a) State outcomes for (case 2-S1); (b) State outcomes for (case 2-S2); (c) State outcomes for (case 2-S3); (d) State outcomes for (case 2-S4).

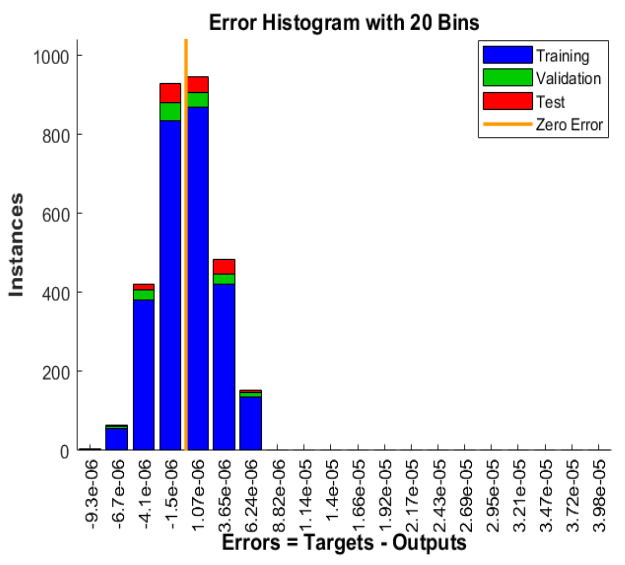

(a)

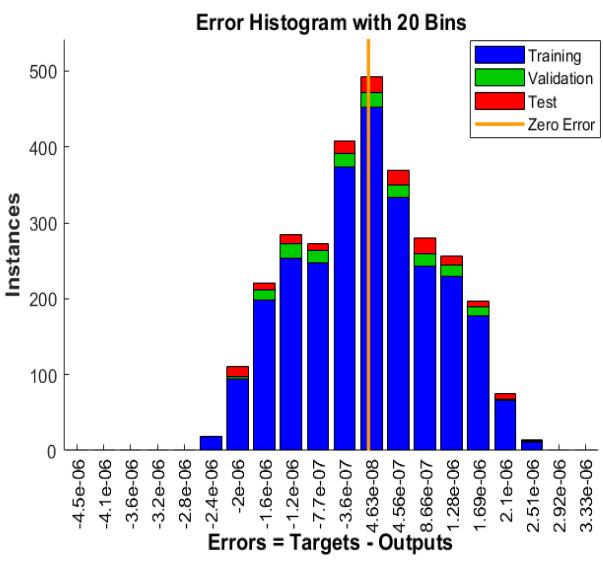

(b)

Figure 8. Cont. 


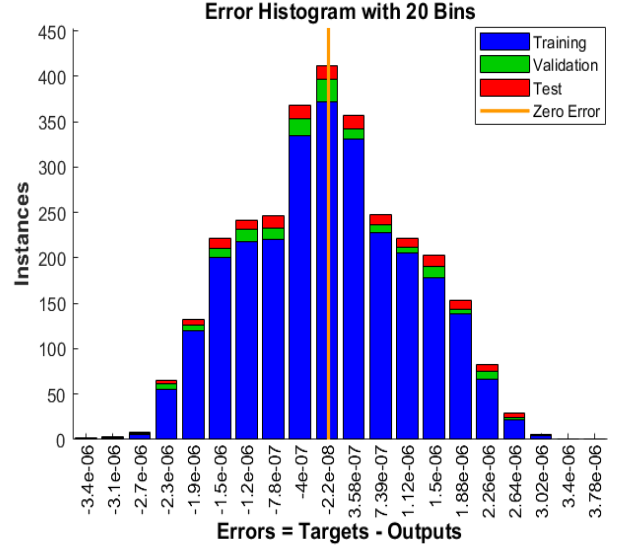

(c)

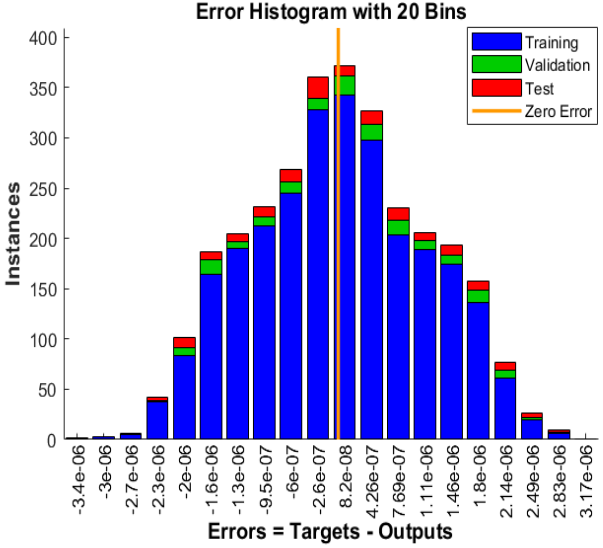

(d)

Figure 8. The error of the histogram of the LMB-NN paradigm for (MHDSF). (a) The error of histogram for (case 2-S1); (b) The error of histogram for (case 2-S2); (c) The error of histogram for (case 2-S3); (d) The error of histogram for (case 2-S4).
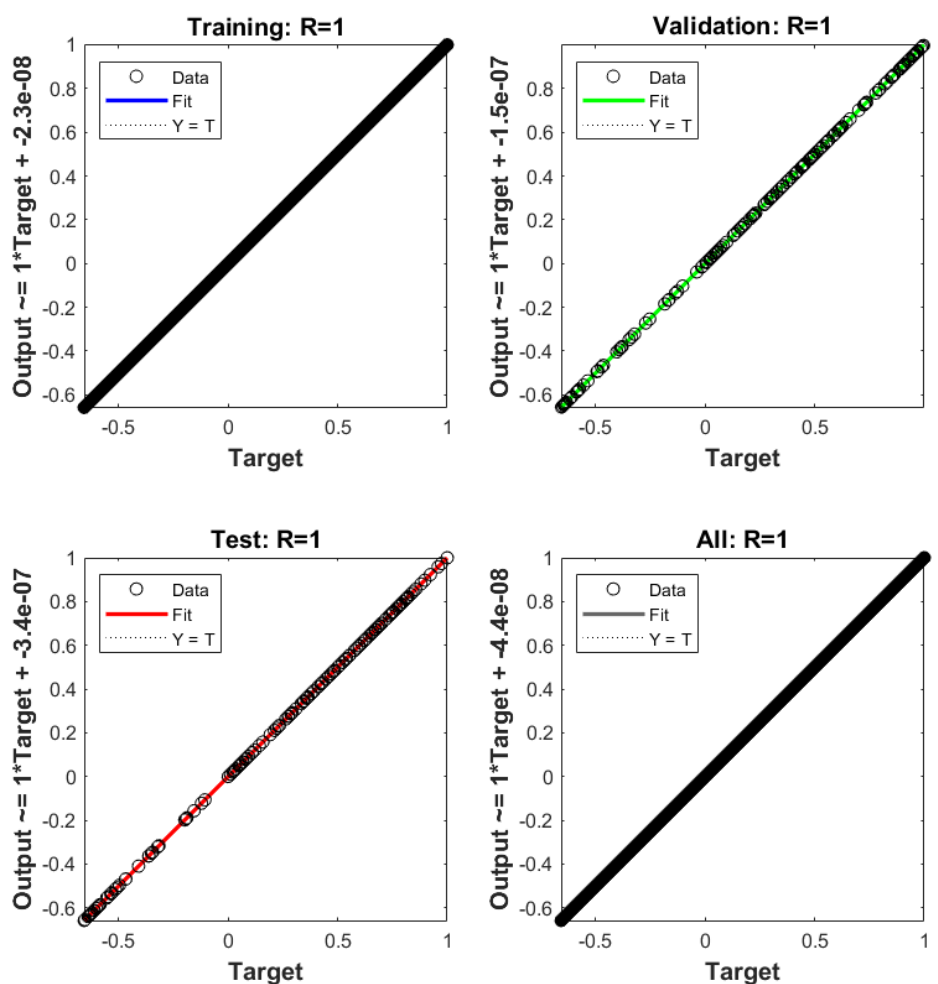

(a)

Figure 9. Cont. 

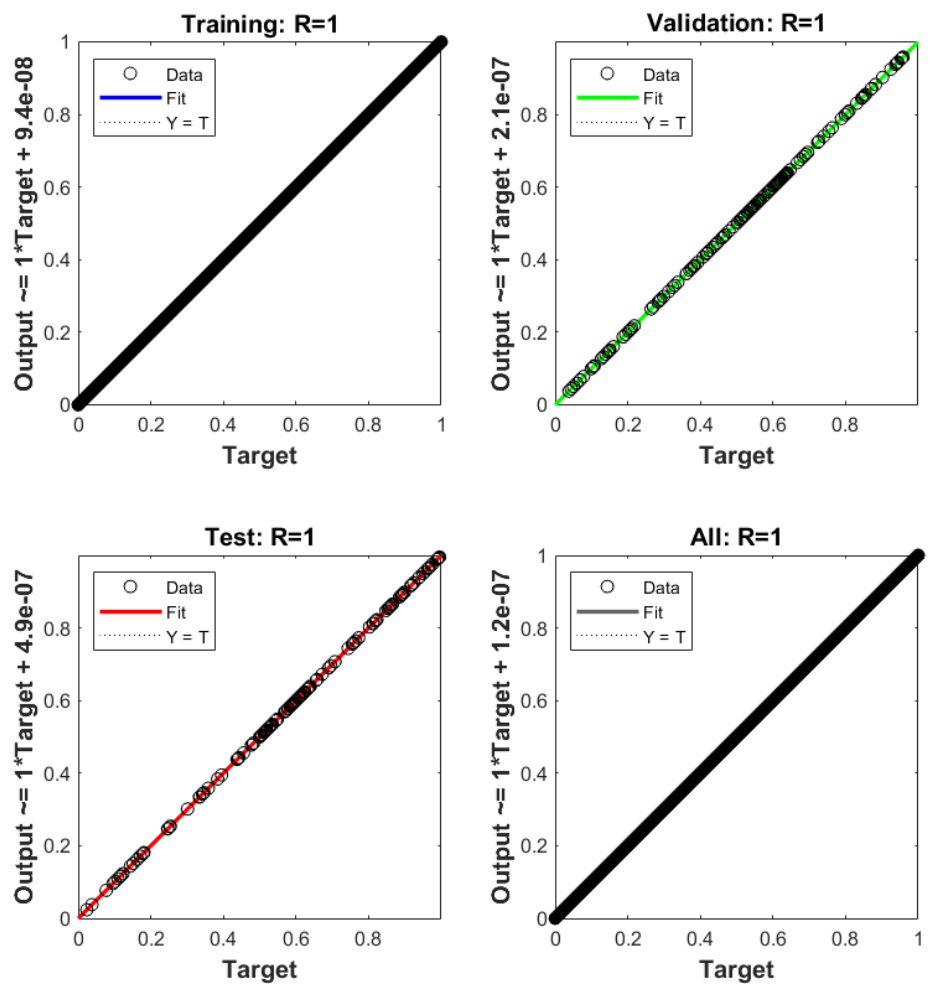

(b)

Figure 9. Regression views of the LMB-NN paradigm for (MHDSF) for (S1-S2). (a) Regression presentation for (case 2-S1) and (b) Regression presentation for (case 2-S2).
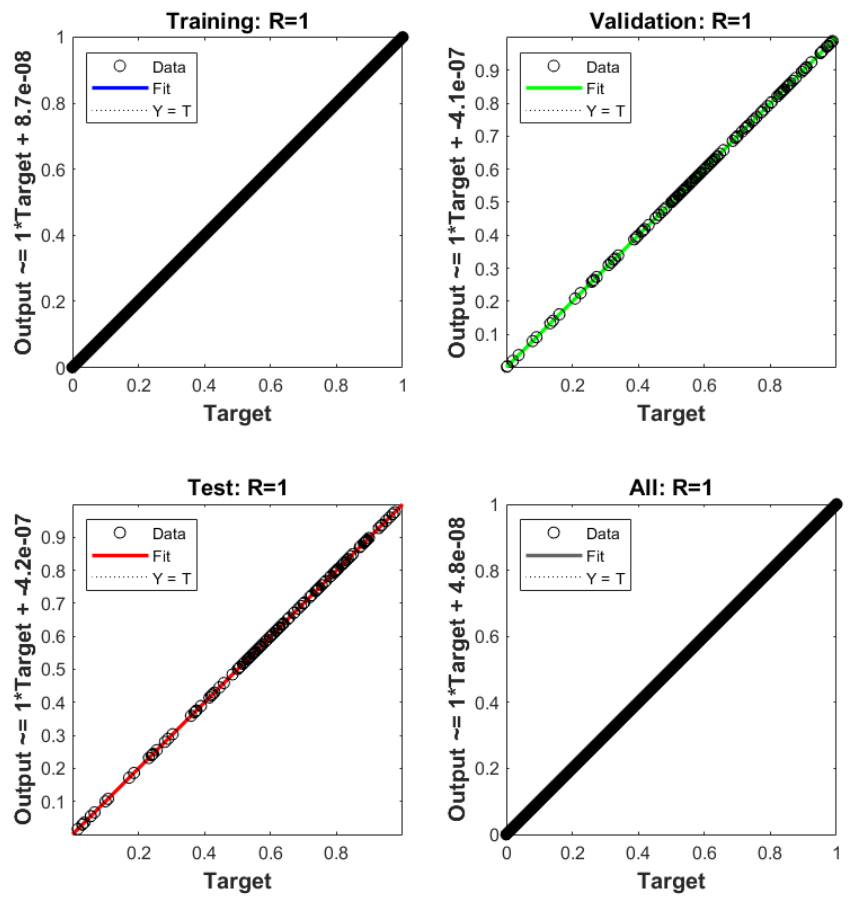

(a)

Figure 10. Cont. 

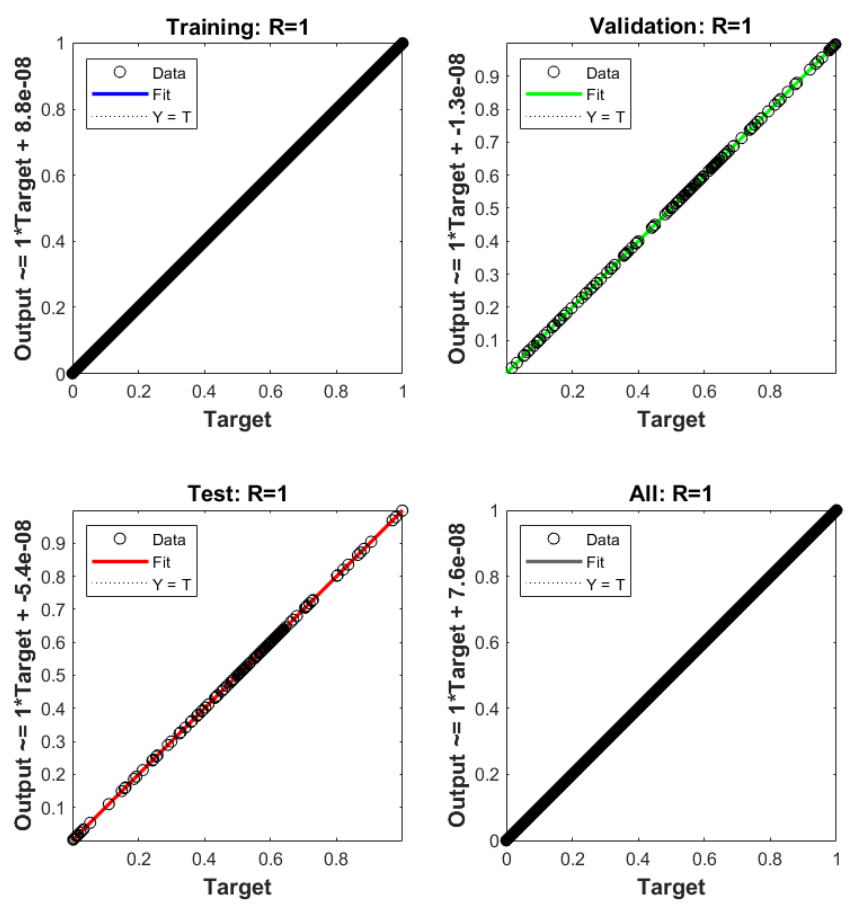

(b)

Figure 10. Regression views of the LMB-NN paradigm for (MHDSF) for (S3-S4). (a) Regression presentation for (case 2-S3) and (b) Regression presentation for (case 2-S4).

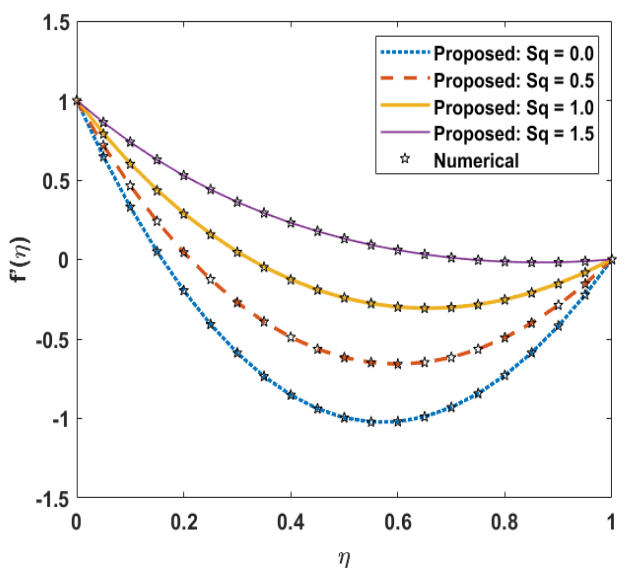

(a)

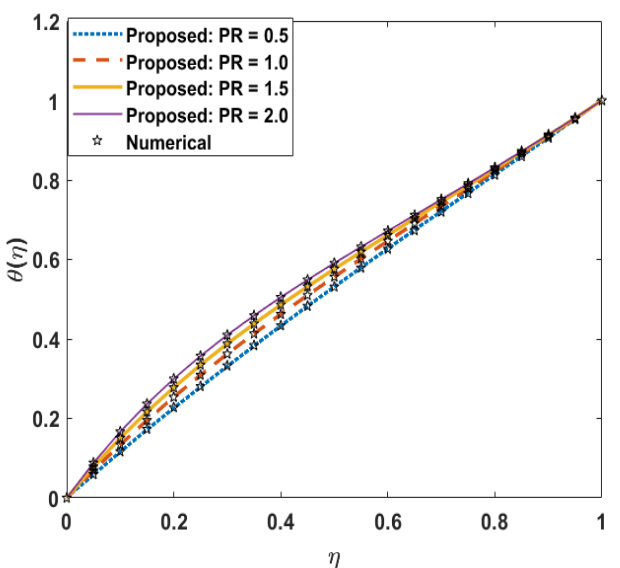

(b)

Figure 11. Cont. 


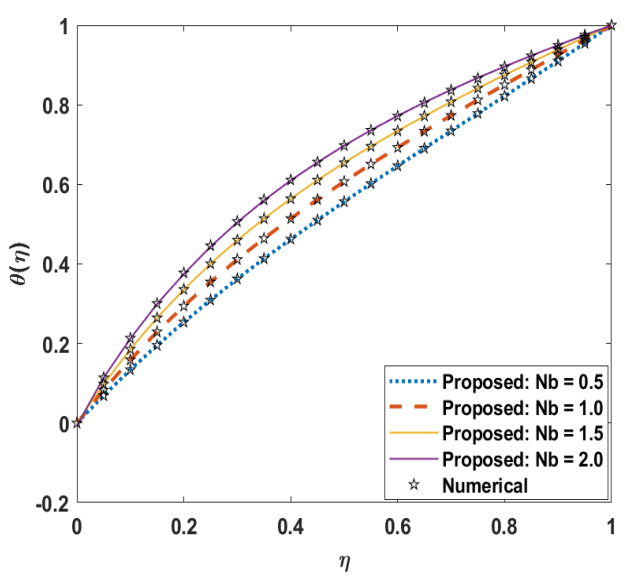

(c)

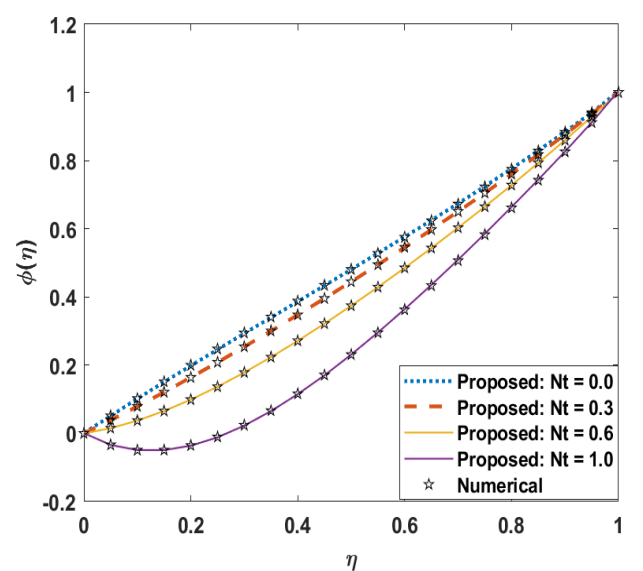

(d)

Figure 11. Comparison of obtained results through LMB-NN for case 2 for the (MHDSF) model. (a) Variation of $S q$; (b) Variation of $P R$; (c) Variation of $\mathrm{Nb}$; (d) Variation of $\mathrm{Nt}$.

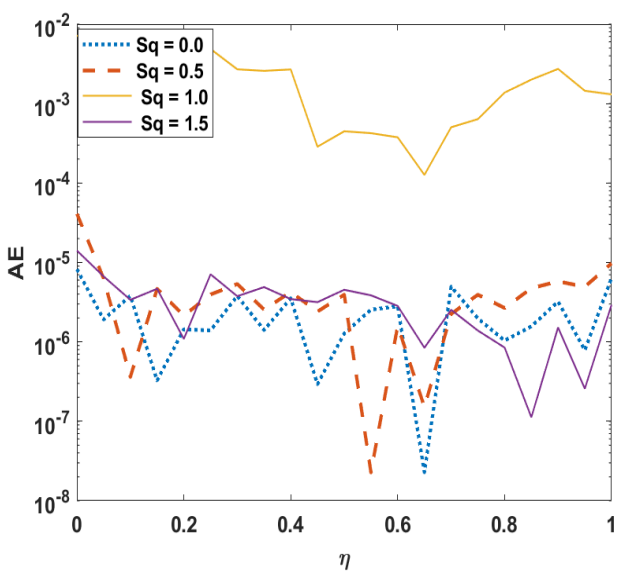

(a)

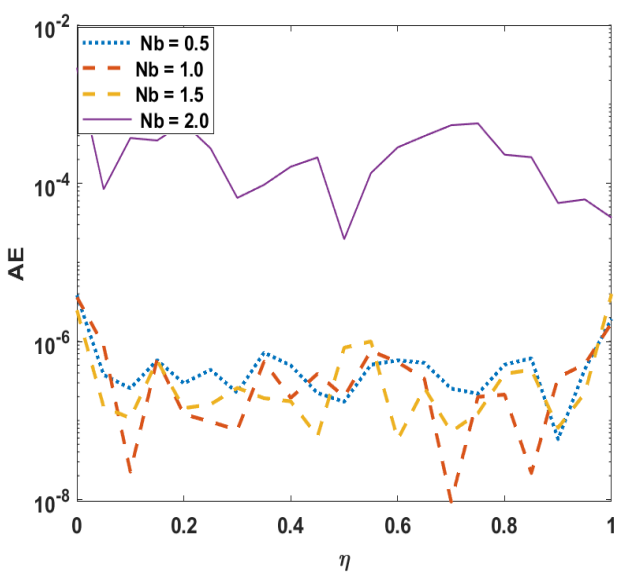

(c)

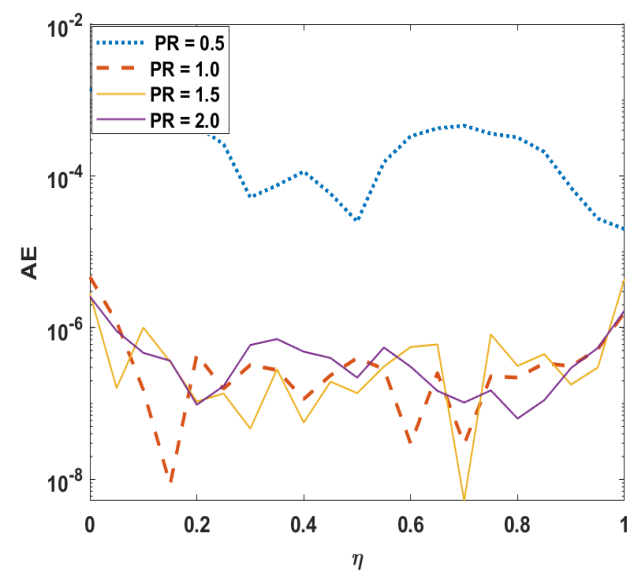

(b)

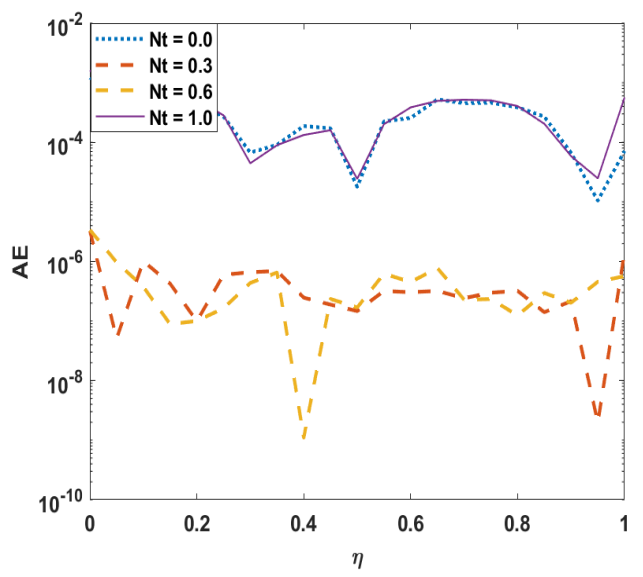

(d)

Figure 12. The absolute error of case 2 for all scenarios of the (MHDSF) model. (a) Analysis on AE of S1; (b) Analysis on AE of S2 (c); Analysis on AE of S3; (d) Analysis on AE of S4.

\section{Conclusions}

Modern artificial intelligence computing is developed to obtain numerical results for the governing mathematical formulation (MHDSF) analysis using the Levenberg- 
Marquardt backpropagated algorithm. These results are compared with standard solutions that come with the help of the explicit Runge-Kutta method. The best compatibility is achieved around $10^{-6}$ to $10^{-3}$, which means that the consistent accuracy of the (LMB-NN) is investigated. Notice that the velocity profile increases with the squeezing parameter $S q$, while the temperature profile is enhanced with higher Prandtl number PR values. Otherwise, the increase of the parameter of Brownian motion $\mathrm{Nb}$ enhanced the temperature profile; in addition, the concentration profile decreases when the thermophoresis parameter values are $\mathrm{N} t$ increasing. New $\mathrm{AI}$ algorithms will be improved to obtain more accurate results in the future $[35,36]$.

Author Contributions: M.A.Z.R. and M.S. suggested the idea. E.S.A. led and supervised the research. M.M.A. wrote the first draft of the paper and obtained the graphical and table results. D.A.M. indicated many important analyses and insights. All authors discussed the numerical results and contributed to manuscript completion. All authors have read and agreed to the published version of the manuscript.

Funding: This project was funded by the Deanship of Scientific Research (DSR), King Abdulaziz University, under Grant No. (KEP-Msc-17-130-41).

Institutional Review Board Statement: Not applicable.

Informed Consent Statement: Not applicable.

Data Availability Statement: Not applicable.

Acknowledgments: The authors acknowledge with thanks to DSR technical and financial support.

Conflicts of Interest: The authors declare no competing interests.

\section{References}

1. Stefan, J. Versuche über die scheinbare Adhäsion. Ann. Der Phys. 1875, 230, 316-318. [CrossRef]

2. Reynolds, O. IV. On the theory of lubrication and its application to Mr. Beauchamp tower's experiments, including an experimental determination of the viscosity of olive oil. Philos. Trans. R. Soc. Lond. 1886, 177, 157-234.

3. Atlas, M.; Haq, R.U.; Mekkaoui, T. Active and zero flux of nanoparticles between a squeezing channel with thermal radiation effects. J. Mol. Liq. 2016, 223, 289-298. [CrossRef]

4. Domairry, G.; Hatami, M. Squeezing Cu-water nanofluid flow analysis between parallel plates by DTM-Padé Method. J. Mol. Liq. 2014, 193, 37-44. [CrossRef]

5. Domairry, G.; Aziz, A. Approximate analysis of MHD squeeze flow between two parallel disks with suction or injection by homotopy perturbation method. Math. Probl. Eng. 2009, 2009, 603916. [CrossRef]

6. Buongiorno, J. Convective transport in nanofluids. J. Heat Transf. 2006, 128, 240-250. [CrossRef]

7. Khan, W.A.; Pop, I. Boundary-layer flow of a nanofluid past a stretching sheet. Int. J. Heat Mass Transf. 2010, 53, 2477-2483. [CrossRef]

8. Turkyilmazoglu, M. Exact analytical solutions for heat and mass transfer of MHD slip flow in nanofluids. Chem. Eng. Sci. 2012, 84, 182-187. [CrossRef]

9. Masuda, H.; Ebata, A.; Teramae, K. Alteration of thermal conductivity and viscosity of liquid by dispersing ultra-fine particles. Dispersion of $\mathrm{Al}_{2} \mathrm{O}_{3}, \mathrm{SiO}_{2}$ and $\mathrm{TiO}_{2}$ ultra-fine particles. NETSU BUSSEI 1993, 7, 227-233. [CrossRef]

10. CChoi, S.U.S.; Eastman, J.A. Enhancing Thermal Conductivity of Fluids with Nanoparticles; No. ANL/MSD/CP-84938; CONF-95113529; Argonne National Lab.: Lemont, IL, USA, 1995.

11. Eastman, J.A.; Choi, S.U.S.; Li, S.; Yu, W.; Thompson, L.J. Anomalously increased effective thermal conductivities of ethylene glycol-based nanofluids containing copper nanoparticles. Appl. Phys. Lett. 2001, 78, 718-720. [CrossRef]

12. Shoaib, M.; Raja, M.A.Z.; Sabir, M.T.; Awais, M.; Islam, S.; Shah, Z.; Kumam, P. Numerical analysis of 3D MHD hybrid nanofluid over a rotational disk in the presence of thermal radiation with Joule heating and viscous dissipation effects using Lobatto IIIA technique. Alex. Eng. J. 2021, 60, 3605-3619. [CrossRef]

13. Nagoor, A.H.; Alaidarous, E.S.; Sabir, M.T.; Shoaib, M.; Raja, M.A.Z. Numerical treatment for three-dimensional rotating flow of carbon nanotubes with Darcy-Forchheimer medium by the Lobatto IIIA technique. Aip Adv. 2020, 10, 025016. [CrossRef]

14. Shoaib, M.; Raja, M.A.Z.; Sabir, M.T.; Islam, S.; Shah, Z.; Kumam, P.; Alrabaiah, H. Numerical investigation for rotating flow of MHD hybrid nanofluid with thermal radiation over a stretching sheet. Sci. Rep. 2020, 10, 1-15. [CrossRef]

15. Bukhari, A.H.; Sulaiman, M.; Raja, M.A.Z.; Islam, S.; Shoaib, M.; Kumam, P. Design of a hybrid NAR-RBFs neural network for nonlinear dusty plasma system. Alex. Eng. J. 2020, 59, 3325-3345. [CrossRef]

16. Bukhari, A.H.; Raja, M.A.Z.; Sulaiman, M.; Islam, S.; Shoaib, M.; Kumam, P. Fractional neuro-sequential ARFIMA-LSTM for financial market forecasting. IEEE Access 2020, 8, 71326-71338. [CrossRef] 
17. Bukhari, A.H.; Sulaiman, M.; Islam, S.; Shoaib, M.; Kumam, P.; Raja, M.A.Z. Neuro-fuzzy modeling and prediction of summer precipitation with application to different meteorological stations. Alex. Eng. J. 2020, 59, 101-116. [CrossRef]

18. Ahmad, I.; Ilyas, H.; Urooj, A.; Aslam, M.S.; Shoaib, M.; Raja, M.A.Z. Novel applications of intelligent computing paradigms for the analysis of nonlinear reactive transport model of the fluid in soft tissues and microvessels. Neural Comput. Appl. 2019, 31, 9041-9059. [CrossRef]

19. Waseem, W.; Sulaiman, M.; Kumam, P.; Shoaib, M.; Raja, M.A.Z.; Islam, S. Investigation of singular ordinary differential equations by a neuroevolutionary approach. PLoS ONE 2020, 15, e0235829. [CrossRef] [PubMed]

20. Waseem, W.; Sulaiman, M.; Islam, S.; Kumam, P.; Nawaz, R.; Raja, M.A.Z.; Farooq, M.; Shoaib, M. A study of changes in temperature profile of porous fin model using cuckoo search algorithm. Alex. Eng. J. 2020, 59, 11-24. [CrossRef]

21. Ilyas, H.; Ahmad, I.; Raja, M.A.Z.; Shoaib, M. A novel design of Gaussian WaveNets for rotational hybrid nanofluidic flow over a stretching sheet involving thermal radiation. Int. Commun. Heat Mass Transf. 2021, 123, 105196. [CrossRef]

22. Khan, I.; Raja, M.A.Z.; Shoaib, M.; Kumam, P.; Alrabaiah, H.; Shah, Z.; Islam, S. Design of Neural Network With LevenbergMarquardtt and Bayesian Regularization Backpropagation for Solving Pantograph Delay Differential Equations. IEEE Access 2020, 8, 137918-137933. [CrossRef]

23. Sabir, Z.; Umar, M.; Guirao, J.L.; Shoaib, M.; Raja, M.A.Z. Integrated intelligent computing paradigm for nonlinear multi-singular third-order Emden-Fowler equation. Neural Comput. Appl. 2020, 33, 1-20. [CrossRef]

24. Sabir, Z.; Raja, M.A.Z.; Umar, M.; Shoaib, M. Design of neuro-swarming-based heuristics to solve the third-order nonlinear multi-singular Emden-Fowler equation. Eur. Phys. J. Plus 2020, 135, 1-17. [CrossRef]

25. Sabir, Z.; Raja, M.A.Z.; Guirao, J.L.; Shoaib, M. Integrated intelligent computing with neuro-swarming solver for multi-singular fourth-order nonlinear Emden-Fowler equation. Comput. Appl. Math. 2020, 39, 1-18. [CrossRef]

26. Umar, M.; Sabir, Z.; Raja, M.A.Z.; Aguilar, J.G.; Amin, F.; Shoaib, M. Neuro-swarm intelligent computing paradigm for nonlinear HIV infection model with CD4+ T-cells. Math. Comput. Simul. 2021, 188, 241-253. [CrossRef]

27. Shoaib, M.; Raja, M.A.Z.; Sabir, M.T.; Bukhari, A.H.; Alrabaiah, H.; Shah, Z.; Kumam, P.; Islam, S. A Stochastic Numerical Analysis Based on Hybrid NAR-RBFs Networks Nonlinear SITR Model for Novel COVID-19 Dynamics. Comput. Methods Programs Biomed. 2021, 202, 105973. [CrossRef]

28. Ahmad, I.; Raja, M.A.Z.; Ramos, H.; Bilal, M.; Shoaib, M. Integrated neuro-evolution-based computing solver for dynamics of nonlinear corneal shape model numerically. Neural Comput. Appl. 2020, 33, 5753-5769. [CrossRef]

29. Umar, M.; Raja, M.A.Z.; Sabir, Z.; Alwabli, A.S.; Shoaib, M. A stochastic computational intelligent solver for numerical treatment of mosquito dispersal model in a heterogeneous environment. Eur. Phys. J. Plus 2020, 135, 1-23. [CrossRef]

30. Faisal, F.; Shoaib, M.; Raja, M.A.Z. A new heuristic computational solver for nonlinear singular Thomas-Fermi system using evolutionary optimized cubic splines. Eur. Phys. J. Plus 2020, 135, 1-29

31. Uddin, I.; Ullah, I.; Raja, M.A.Z.; Shoaib, M.; Islam, S.; Muhammad, T. Design of intelligent computing networks for numerical treatment of thin film flow of Maxwell nanofluid over a stretched and rotating surface. Surf. Interfaces 2021, 24, 101107. [CrossRef]

32. Shoaib, M.; Raja, M.A.Z.; Khan, M.A.R.; Farhat, I.; Awan, S.E. Neuro-Computing Networks for Entropy Generation under the Influence of MHD and Thermal Radiation. Surf. Interfaces 2021, 25, 101243. [CrossRef]

33. Aljohani, J.L.; Alaidarous, E.S.; Raja, M.A.Z.; Shoaib, M.; Alhothuali, M.S. Intelligent computing through neural networks for numerical treatment of non-Newtonian wire coating analysis model. Sci. Rep. 2021, 11, 1-32. [CrossRef] [PubMed]

34. Hayat, T.; Muhammad, T.; Qayyum, A.; Alsaedi, A.; Mustafa, M. On squeezing flow of nanofluid in the presence of magnetic field effects. J. Mol. Liq. 2016, 213, 179-185. [CrossRef]

35. Shoaib, M.; Akhtar, R.; Khan, M.A.R.; Rana, M.A.; Siddiqui, A.M.; Zhiyu, Z.; Raja, M.A.Z. A Novel Design of Three-Dimensional MHD Flow of Second-Grade Fluid past a Porous Plate. Math. Probl. Eng. 2019, 2019, 584397. [CrossRef]

36. Imran, A.; Akhtar, R.; Zhiyu, Z.; Shoaib, M.; Zahoor Raja, M.A. MHD and heat transfer analyses of a fluid flow through scraped surface heat exchanger by analytical solver. Aip Adv. 2019, 9, 075201. [CrossRef] 